\title{
Paradigm Shift In Indian Banking Industry With Special Reference To Artificial Intelligence
}

\author{
Khusboo Srivastava ${ }^{a}$, Dr. Somesh Dhamija ${ }^{b}$ \\ aAssistant Professor, GLA University, Mathura-UP, India. E-mail: khusboo.srivastava@gla.ac.in \\ bProfessor, GLA University, Mathura-UP, India. E-mail: somesh.dhamija@gla.ac.in
}

Article History: Received: 11 January 2021; Accepted: 27 February 2021; Published online: 5 April 2021

\begin{abstract}
Technological advancement has transformed the businesses environment in past few decades and many technologies will emerge that will profoundly influence many industries. This technology revolution is future and controlling the organizations effortlessly for productive development. The paper investigates the various zones where the Artificial Intelligence is being utilized in the Indian banking sector and also its implications. This paper will confer that what are the advantages and the challenges which artificial intelligence is confronting in India. It seeks to explore advancement that artificial intelligence offers to FinTech and the different ways in which it can shape the operations of an Indian banking ecosystem.
\end{abstract}

Keywords: Machine Learnings, Chatbots, Fraud Detection and Customers.

\section{Introduction}

Artificial intelligence (AI) is the branch of Computer science that manages the machines that are programmed linked to exhibits the human traits of thinking, learning and self-revision. AI is interdisciplinary by nature and has virtually created a paradigm shift in every sector of technology based industry. Probability of applying machine intelligence in different fields is extensive. With ongoing improvement in both equipment and programming advancements had expanded the application of artificial intelligence framework. It has its presence in diverse field of optical communications, network planning, programming, transportation systems, clinical science, electronic trading, robot control, and remote sensing to give some examples. Advancement in the complex algorithms of machine learning and deep learning has structured machine to mimic the cognitive functions of human mind and acquire competence of superior decision making (Mata et al., 2018). It has penetrated numerous other sectors industries encompassing finance, healthcare, education, transportation, Heavy industries, Hospitality, HR, marketing, even in politics.

In the assessment of Mannino et al., (2015), machine intelligence framework is more proficient and predominant than minds of human. It has been analyzed that number of street mishaps diminished and similarly clinical diagnostics turned out to be increasingly exact with the utilization of Artificial intelligence effect. Artificial intelligence is consist of three advanced technologies - machine learning, natural language processing and cognitive computing. Further improvement of pertinent algorithms will complement in creating superhuman intelligence of different programmed process in coming decades.

Man-made intelligence (AI) is emerging with advanced technologies all over the globe. It is indicating signs of acceptance by integrating with different enterprises and permitting them to embrace AI for different applications. It is today's reality that it is affecting our lives quicker than we can envision. It is now omnipresent, from Siri in our telephone to the Netflix availability that we get on our TV set. The reformation brought by artificial insight has been the greatest. There can be no denial that artificial insight will turn into a pivotal and indispensable piece of our life. Hoadley and Lucas (2018) defined AI as framework that performs under various situations even without critical human oversight, also learn from their experience and may even tackle undertakings requiring human-like recognition, discernment, arranging, learning, correspondence or physical activities. Computer based intelligence have been connected to frameworks that think like people, act like people, think judiciously or act normally. The idea of artificial intelligence is to reproduce the intelligence of human in machines with the assistance of refined AI and machine algorithms to defeat the limitation of intelligence of the human. Man-made intelligence hopes to beat limit to speed with which human work by moving the human intelligence into machines with preeminent computational capacities.

Vempati (2016) discussed over various facets of artificial intelligence revolution in India. AI speaks of a revolution in finance industry by furnishing clients with more prominent worth and expanding firms' incomes (Park et al., 2016). For occasion, Bank of America utilize a chatbot known as Erica to address fundamental financial inquiries (Rosman, 2018). Another stunning model is the situation of a humanoid named as Nau that 
goes to clients along with bank officials in certain branches of the Bank of Tokyo (Marinova et al., 2017). However, the most interesting developments under FinTech which assists the investment management has been robo advisor. Faubion, 2016; Park et al., 2016 claimed that robo advisor lessen charges and provide all time access to finance than that of services from human advisor. Thus, these self-governing frameworks are required to democratize the utilization of service of financial advice to more extensive number of clients (Sironi, 2016). Though its adoption is not quick as per Jung et al 2018. The wonder of remarkable development of AI and robotbased frameworks across industries is critically affecting the financial, social and other areas (Acemoglu and Restrepo, 2020), researchers are concentrating on introducing AI based services including robots, droids (Singh et al., 2017; Han and Yang, 2018), even Grewal et al. (2017) anticipated that AI frameworks (for example Alexa, Cortana, Siri) would legitimately affect purchasing behavior of consumers. Now firms also understand the relevance AI to advance their administration practices and modify their product (Han and Yang, 2018). Artificial intelligence in banking and different aspects of financial arena is now having more association as it assist their customers better, enhance the operational efficiency and helps in cost saving.

\section{Evolution}

In spite of the fact that, it is as of late that we have seen the use of AI, the historical backdrop of AI returns to the 1950s where a paper was published by Alan Turing about the test of machine's ability to exhibit acumen. The term "Artificial intelligence" was instituted in 1956 during a workshop at Dartmouth College by John McCarthy (Russell and Norvig, 1995). AI has become increasingly famous today due to its huge information volumes, advanced algorithms, and upgraded computing power and capacity. During the 1950s, subjects like critical thinking and symbolic approach were explored by AI. During the 1960s, the US Department of Defense looked into this kind of work and started preparing PCs to emulate fundamental human reasoning. Russell and Norvig (1995) demarcated four aspects of AI "to think like a human, to act like a human, to think rationally and to act rationally". Huang and Rust, 2018 affirmed that these four aspects of AI encompasses various fields like psychology, management, healthcare, computer programming. In 2003 itself, Defense Advanced Research Projects Agency shaped virtual personal assistants and that smoothened the path for the mechanization and proper thinking including support systems for decisions and smart search systems that we find in PCs today to supplement and expand human competence. The pace of AI just got after 2011, wherein conspicuous tech organizations began putting resources into artificial intelligence and machine learning for its applications in business. Microsoft made debut with intelligent personal assistant named Cartana and Apple with Siri. The pattern of technology was then adopted to make a program that dominated Atari matches. Facebook additionally sponsored AI with the applications that distinguish faces in photographs shared to companions. Presently AI is said to be the heart of fourth industry revolution.

\section{AI in Banking Sector}

Indian banking segment is one of the principal adopters of AI but its espousal has been gradual in comparison to other sector because banking is as yet manpower driven division, with activities that require human inclusion. Now it is the time for Indian Banking to comprehend the need to reduce expense and the time consumption on repetitive assignments. Like other sectors, banks have also started exploring and incorporating the innovation in different banking functions. AI reboots the banking system by the presence of intelligent chat-bots for client support, customized services, and setting AI robots at banks for self-administration. Moreover banks are utilizing the innovation for achieving proficiency to their back-office, reduction in frauds and risk related to security. As indicated by Fintech India report 2017 by PwC, the global expenditure on AI applications has reached to $\$ 5.1$ billion from $\$ 4$ billion in 2015. According to furman and seamans (2018), AI applications is having positive impact over the growth of economy and development. Mainly all business and investment banks all around are consolidating AI and blockchain for both back-office and client confronting purposes.

Though artificial intelligence in Indian banking is in its nascent stage and this technology adoption has not yet worked out as intended. The Indian banking system is investigating the ways by which the intensity of AI can be applied to improve the procedures and upgrade the customer service can be transformed and the Indian financial Sector is progressively moving itself towards utilizing AI. In banks, data is fundamental requirement for all business lines, from deposits and advances to investments and portfolio management. Independent management of data without human contribution consequently offers extraordinary open doors for banks to improve speed, precision and productivity. AI applications in banking can be arranged into four general classes: 1) client centered front office applications; 2) banking operations centered back office applications 3 ) investment management 4) Regulatory compliance.

AI implementation in banking. 


\begin{tabular}{|c|c|c|c|}
\hline \multicolumn{4}{|c|}{$\begin{array}{l}\text { client centered fr banking operations centered back of investment managen Regulatory compliance } \\
\text { office }\end{array}$} \\
\hline Credit scoring & Capital optimization & Trade execution & Regulatory technology \\
\hline Insurance policies & Model risk management & Portfolio managemen 1 & Macroprudential surveill: \\
\hline Client-facing chat & Stress testing & & Data quality assurance \\
\hline Know your custor & Fraud detection & & Supervisory technology \\
\hline
\end{tabular}

Source: FSB (2017), Deutsche Bank Research

Banks have started exploring different avenues of AI based technologies instead of completely depending on it for their banking functions. Customers and banking operations centered AI applications appear to experience more appreciation than others. AI is being tried on real time basis for detection and counteraction of any fraud in banking services. AI is likewise used in KYC procedures for the identification of customers and also to raise warning in case of any inconsistency during KYC check. Another triumph in AI advancements is chatbots, a form of digital assistance that communicates with bank customers by text or voice and intends to address the customer's request without the inclusion of a bank representative. Banks are likewise utilizing AI for instance to extract data from legal records or yearly reports and to extricate any important clause. Some financial related innovation are unique too, robo-advisors is fully automated tool to assist in financial planning of customers. It turn out to be progressively proficient, banks for the most part appear to investigate AI applications to supplant activities which are expensive, labor extensive and redundant.

Banks are presently embracing AI which can be the future of banking as it aids in strengthening the competitiveness of banks including AI based algorithms and common language processing - application-based service, cloud storage and real time management of data. Different AI applications have been incorporated banking across different divisions like core banking, operation productivity, client confronting services and advanced data analytics. With the AI, banking will never be confined to applications, websites or physical branches but it will mark presence in every AI driven functions. As per Business insider index research, Aggregate cost saving from banks by the applications of AI tools is estimated at $\$ 447$ billion by 2023 . The emphasis is on management of risk related to operations and functioning of banks like identification of any fraud or improved KYC. In fact $80 \%$ banks are aware about the AI driven benefits so are embraced or planning to implement AI solutions in the system.

Highlighted are the six key areas of Artificial intelligence in the Banking business that are creating remarkable change.

\section{a). AML Pattern Detection}

Many significant banks over the globe are now moving from rule based programming frameworks to machine intelligence based frameworks which has more prominence in the countering money laundering. Its implementation in the middle office functions of the banks is used to detect suspicious data activities where AI algorithms check customer records and assess the authentication of the data given by customer over data available on internet to control and prevent fraud payments and to improve the anti money laundering (AML) by keeping eye on know your customer (KYC) process. these frameworks are just set to turn out to be more appropriate and quick with the innovative devices in the field of artificial intelligence in next coming years.

\section{b). Chat bots \& Humanoid Robots}

Humanoid Chatbot can be used to revolutionize the efficient management of bank and customer relationship and also reduce cost of banking operations. Chatbots are the automated conversation like interfaces through which organizations convey their information combined with natural language processing and cognitive machine give clients various kinds of information. In chatbots, the framework is taken care of with common language information based on previous client association records, which is handled by AI framework that figures out how to propose appropriate text /audio replies back to the client automatically. The development of AI and chatbots has opened new roads for utilizing client information to profit firms as well as clients' experience with the banks. Most recent innovation utilized in AI chatbots incorporate methodologies for learning word representation (Bojanowski et al., 2016) and classification of text (Joulin et al., 2016). Today, chatbots are by and large progressively utilized in providing virtual assistance to different customer services in banking and finance (Behera, 2016). Followings are chatbots empowered banks in india: SBI has strengthen with its own Artificial Intelligence based chatbot SIA (SBI Intelligent Assistant) who will deal with client questions by giving out data on SBI's offering on products and services. The bank is right now employing an AI driven arrangement created by Chapdex (winning team from its first hackathon), that catches the face of the clients for understanding the 
conduct of its clients. Other similar digital devices is SBI inTouch which is also utilizing bots and AI so that men and machines can coexist in banks to easily handle problem handling operations of bank related to usual FAQs, banking services and payment requests in cost effective way. Yes Bank is evolving with the YES Pay Bot which is for payment wallet, another Yes Tag's Chatbot permits client for 5 banking transactions in 5 distinctive applications to monitor their account balance, mini statement, details of FDs, cheques, fund transfers and many more. A banking chatbot for its credits and advances is known as YES mpower. It assists clients with getting data about of loans offered by the bank. ICICI Bank, in 2016 had presented the software robotics for banking operations. It carries activities to mechanize and do superfluous, many business functions. DBS Bank's Digibank is India's first chatbot staffed mobile bank that can address all the banking related questions progressively. Chatbot known as KAI is inspired by New York based firm Kasisto that has a set AI driven system on different banking questions that can be inquired by clientele. To empower Indian banking sector, other banks like Axis Bank collaborated with Singapore-based active artificial intelligence to introduce conversational interface for their customers. HDFC bank's EVA, is virtual assistant for directing customers related to the banking product and services. The chatbot can answer a huge number of client questions over numerous channels. It has as of late launched Humanoid robot IRA in a portion of its branches. Similarly the humanoid Lakshmi, by City Union Bank, is an amicable AI fueled robot that can interact with clients on various banking aspects. This is the first robot presented in any bank in India. Canara Bank as of late propelled Kannada talking robot MITRA which tunes in to the client inquiries.

\section{c). Algorithmic Trading}

AI models is being deployed over the globe for lot of Hedge funds by picking the inputs from different resources for understanding the volatility in financial markets and sentiments associated with investment decisions. It has been reported that over $70 \%$ of the trading today is really done via artificial intelligence frameworks. When there is identification of trading opportunity dependent on the information sources, the majority of investments of hedge funds follow various AI models for making high frequency trades (HFTs).

In 2015, the Emerging Opportunities Engine purportedly utilizes AI and natural language processing to recognize customers' best time for follow on equity .The innovation has demonstrated effective in equity capital markets and debt capital markets.

\section{d). Detection of Frauds}

New AI Landscape opportunity in banking is detection of fraudulent online transactions which has provided exact and unrivalled outcomes with the mediation of artificial intelligence. It is one of area of major concern in banking where machine intelligence frameworks have exceeded expectations (Yeoh 2019). Falcon fraud assessment system has deployed data analytics in banking and is based on a neural network shell for fraud detection. Without a doubt, credit card related frauds are predominant types of cybercrime which got intensified by the development of payments modes such as mobile banking and online banking. To track the fraudulent activity, AI algorithms are also designed to even track customers' credit card transactions in real time. It blocks the transactions in the event of any risk by comparing all new transactions with past locations and amount of transaction. Banks are leveraging AI for automated management of risk which mainly includes compliance regulation and detection of fraud. The Anomaly detection device would alert the bank and customer. Mastercard has collaborated with Brighterion which uses machine learning innovation to give real time intelligence from all available information.

\section{e). Customer Recommendations}

Artificial intelligence encompasses number of cognitive technologies which are the key opportunities in financial services. Cognitive engagement solutions is used to build customer understanding model by collecting the information from past or various selection of banking offering, customer activation by communicating in personalized way, influencing desired actions. Recommendation engines exploring cognitive engagement can now give quick, customized services to the customers. Cognitive systems make appropriate recommendation to the customers based on the power of unlocking their preference and history thus act as competent device in revenue offers personalized engagement between banks and their customers by managing every client and concentrating on their prerequisites. JPMorgan had launched a predictive recommendation engine to forecast the behavior of the investors.

\section{f). Others}

Manning, 2018 proclaimed that applying AI in Indian banking system can make the banking operations increasingly significant and convenient. S Da Costa 2018 also discussed that there are some regions in banking 
system, where it can be effectively be applied .Those can be tailored services related to Finance: Artificial intelligence can help in analyzing security market and give suggestions according to financial objectives of individual clients. Automated financial advisors aid in making investment decisions after analyzing the relationship between the risk profile and financial goal of the customer thus this personalized interface has arrived at new dimension. Underwriting: The insurance segment is also now using AI enabled automation in the process of underwriting. Automation of this procedure with the utilization of AI administrations that can utilize unstructured data in the procedure of making decision. Voice Aided Banking: A cognitive insight engages clients for banking services with voice instruction and touch screens. The natural language technology can process inquiries to address questions, discover data, and associate clients with banks. Language processing utilizing AI can improve proficiency of the procedure and also lessen human error. Information Driven Loaning Decisions: Various AI Applications examines available volume of information and thus provides the customized financial solution, estimations and figures to the customers. Such tools make financial plans and manage the portfolio as per various investment opportunities, advances, rates, expenses, and so on and also track the progress along with updates. Smart Wallets: Digital wallets are new fate of all financial transactions, with giant players like Google, Apple, Paypal and others, entering the new trend and building up their own payment gateway. This declines the reliance on hard cash, accordingly augmenting the reach of money to all thus promoting cashless transaction in India. Client assistance: With natural language processing computers could now able to assist most of its client. This definitely would end long waiting lines and thus result in delightful experience to clients. Digitization of documentation: It facilitates easy banking accessibility and creates a platform to associate customers with banks. Blockchain based payments: Due to revolution of digitalization, the client base that banks serve is experiencing a significant move as far as purchasing practices and inclinations are concerned. Blockchain is set now to provide benefit of real time transactions, consequently expanding the value, support and satisfaction to the customers. Management of risk: Personalized banking products and services can be presented to customers based on past banking history and by analyzing the risk appetite. Security: Conducts suspicious by nature, logins investigation, and spam emails can be perceived beforehand to avoid breaches of security. Digitization and mechanization in handling back-office: Capturing information from data utilizing OCR and then using AI for required content which significantly saves the operations time. AI is being used to support backend office activities that include high volume, regulatory and profoundly structured work. Computer based intelligence advancements are performing automated client on boarding, compliance match, acquiring reports on investments or any data. It has been reported that SBI is using IBM Watson for various banking operations similarly ICICI has settled on an inhouse arrangement, conveying their software robotics devices for such operations. Automation is achieved using $\mathrm{AI}$ is made conceivable by the mix of advanced programming of cognitive automation. Wealth management: Roboadvisor is a device to provide financial advice to the customer or managing the portfolio by considering his financial status, risk profile, anticipated profitability. Predictive models use AI to analyze and draw conclusion with the option to pick the appropriate product for their portfolio. ATMs: recognition of Image/face is done by utilizing real time camera and other AI innovations, deep learning in incorporated at ATMs to avoid and identify any fraud.

\section{Issues and Challenges}

AI is new endeavor towards digitalization and a giant step for the transformation of business processes. It is encountering several issues and challenges on the way of its acceptance and implementation. In India, financial institution and services are their early stage, so their adoption is skeptical mainly around information and its influence on employees.

Notwithstanding its tremendous potential, some extraneous components may hinder AI usage in banking. To start with, the EU's General Data Protection Regulation (GDPR) which contains some preventive measures on dynamics of AI based decision making. This influences all the sectors along with financial industry. Article 22 of the GDPR states: " The data subject shall have the right not to be subject to a decision based solely on automated processing, including profiling..." It is especially a concern for devices whose dimension of decision is exclusively based on AI. To defeat the limitations under Article 22, human intervention at some stage may be an answer. For example toward the completion of the AI chain, final decision must be taken by human. Moreover Article 13 of the GDPR includes provisions for the disclosures. For instance, if an AI device dismisses a customer account or application of a loan, the customer has the right to understand the rationale associated with this choice. Article 13 doesn't really require AI algorithms of the source code to give the details. However some data of the AI instrument must be revealed. Therefore the human involvement may be required so as to have complete compliance to these and numerous other information security controls.

Another impediment in usage of AI in banking is the possibly malevolent control of big data. For instance, any hacker may attempt to flood data framework with fake information (counterfeit social media accounts, sites, 
news) to impact AI dynamics of decision making. Accordingly, AI devices may take one sided choices and victimize certain people, or unauthorized programmers could even control the whole system. AI based systems are inter connected with one another which may result into magnifications of malicious problems. Despite the fact that AI itself has precision in recognizing cyber attacks and malware therefore the consistent supervision of programmers is very important to combat issues related to cyber security. Sandboxes may be valuable in this specific circumstance. For instance, Deutsche Bank's Alpha-Dig platform (Alpha-Dig) gathers all content from news media, online networking, and other common language articles, and afterward constructs an image of a nation's political risk profile. Thus it can measure geopolitical risk and its impact on budgetary markets.

It is necessary to understand that AI based forecast and decision making may be very close to that of humans. In contrast to humans however, AI can't convey its reasoning. This aspect is problematic for the utilization of AI in banking as operations must be rechecked in backward direction regardless of whether the decision made is sensible. In the event that there is discrepancy with decision, it should be corrected at the step where the error has appeared. The decision making procedure must have complete compliance with administrative regulation and principles. While this reverse process might likewise reduce effective gains of AI, the contribution of human software developers and supervisors may be an answer for lessen issues around complex algorithm of AI. In spite of these possible limitations, banks are diving deep into different avenues related AI, which could have noteworthy profitable. There is lot of avenues for applicability of AI in banking sector in India. It is facing many challenges in terms of its acceptance, awareness, and issues with security and information threats. Banks has to overcome these challenge and will have to empower themselves to compete with other fintech firms .

\section{Conclusion}

Banks are investing in AI for regulatory compliance and risk management more than any other business area.AI is rescue tool for making customer experience naturally pleasant and give the taste of ease and convenience. Since use of AI is expanding as while it has backed out various banks operations. It has additionally created automation in the banking system which may not intend to replace human but to give clients a more extravagant $24 / 7$ interaction experience.

Financial arena has lot of advantage due to the adoption of AI based tools and it has shown the paradigm shift in procedures and client confronting services in the financial division in India. It is being employed to meet compliance issues, prevention fraud, and assess the credit worthiness of individual. The utilization of AI can progressively create productive business processes, offer customized services, and aid for acheiving the goals of financial inclusion. This is certain that ongoing push towards digitalization is having the great impact on the conventional models of bank. It has also accelerated digital security threats and vulnerabilities and for that other financial technologies like block chain and other tools are acting as panacea by creating restriction system against financial crimes. Particularly in the US and China, AI has pulled in enormous interests of investors and is progressively being implemented. In Europe, some nations are having a functioning of AI while others fall behind. Considering its potential to revolutionize the business processes and profitability, European policymakers have acquainted measures with increment AI movement in Europe. Until now, however, usage of AI in banking is moderate. All things considered, AI's likely contribution to bank productivity can't be avoided. In a digital revolution situation, Indian banking industry has also to grow to compete with other FinTech new companies and other financial firms.

\section{References}

1. Acemoglu, D., \& Restrepo, P. (2020). Robots and jobs: Evidence from US labor markets. Journal of Political Economy, 128(6), 2188-2244.

2. Behera, B. (2016). Chappie-a semi-automatic intelligent chatbot. Write-Up.

3. Bojanowski, P., Grave, E., Joulin, A., \& Mikolov, T. (2017). Enriching word vectors with subword information. Transactions of the Association for Computational Linguistics, 5, 135-146.

4. Da Costa, S. (2018). How Artificial Intelligence is changing the banking sector.

5. Faubion, B. (2016). Effect of automated advising platforms on the financial advising market.

6. Furman, J., \& Seamans, R. (2019). AI and the Economy. Innovation Policy and the Economy, 19(1), 161-191.

7. Grewal, D., Roggeveen, A.L. and Nordfält, J. (2017), "The future of retailing”, Journal of Retailing, 93(1), pp. 1-6.

8. Han, S., \& Yang, H. (2018). Understanding adoption of intelligent personal assistants. Industrial Management \& Data Systems. Vol. 118 No. 3, pp. 618-636. 
9. Huang, M. H., \& Rust, R. T. (2018). Artificial intelligence in service. Journal of Service Research, 21(2), 155-172.

10. Hoadley, D. S., \& Lucas, N. J. (2018). Artificial intelligence and national security. Congressional Research Service.

11. Joulin, A., Grave, E., Bojanowski, P., \& Mikolov, T. (2016). Bag of tricks for efficient text classification. arXiv preprint arXiv:1607.01759.

12. Jung, D., Dorner, V., Weinhardt, C., \& Pusmaz, H. (2018). Designing a robo-advisor for risk-averse, low-budget consumers. Electronic Markets, 28(3), 367-380.

13. Mannino, A., Althaus, D., Erhardt, J., Gloor, L., Hutter, A., \& Metzinger, T. (2015). Artificial intelligence: Opportunities and risks. Policy Paper by the E_ective Altruism Foundation, 2, 1-16.

14. Marinova, D., de Ruyter, K., Huang, M. H., Meuter, M. L., \& Challagalla, G. (2017). Getting smart: Learning from technology-empowered frontline interactions. Journal of Service Research, 20(1), 29-42.

15. Mata, J., de Miguel, I., Duran, R. J., Merayo, N., Singh, S. K., Jukan, A., \& Chamania, M. (2018). Artificial intelligence (AI) methods in optical networks: A comprehensive survey. Optical switching and networking, 28, 43-57

16. Park, J. Y., Ryu, J. P., \& Shin, H. J. (2016). Robo advisors for portfolio management. Advanced Science and Technology Letters, 141, 104-108.

17. Rogers, E. M. (2010). Diffusion of innovations. Simon and Schuster.

18. Rosman, C. (2018). Mad about Erica: why a million people use bank of America's chatbot. American Banker, New York, NY, available at: www. americanbanker. com/news/mad-about-erica-why-amillionpeople-use-bank-of-americas-chatbot (accessed August 8, 2018).

19. Russell, S., \& Norvig, P. (1995). Intelligent agents. Artificial intelligence: A modern approach, 74, 4647.

20. Singh, J., Brady, M., Arnold, T., \& Brown, T. (2017). The emergent field of organizational frontlines. Journal of Service Research, 20(1), 3-11.

21. Sironi, P. (2016). FinTech innovation: from robo-advisors to goal based investing and gamification. John Wiley \& Sons.

22. Vempati, S. S. (2016). India and the artificial intelligence revolution. Carnegie Endowment for International Peace.

23. Yeoh, P. (2019). Artificial intelligence: accelerator or panacea for financial crime?. Journal of Financial Crime.

24. Are Machines Replacing Bankers. https://www.sbi.co.in/ portal/web/sbi/blogdetail ?blogId=27271874

25. Artificial Intelligence comes to the rescue of banks Banks trusting machines more than humans 2018. https://mediaindia.eu/business-politics/artificial-intelligence-comes-to-the-rescue-of-banks/

26. Artificial intelligence to disrupt wealth management business: PwC. Business Standard. http://www.business-standard.com/article/companies/artificial-intelligence-to-disrupt-wealthmanagement-business-pwc-116060601023_1.html.

27. Banking on the Future: Vision 2020. https://www2. deloitte.com/content/dam/Deloitte/in/Documents/financial-services/in-fs-deloitte-bankingcolloquiumthoughtpaper-cii.pdf.

28. Chatbot: The intelligent banking assistant. Pwc.

29. https://www.pwc.in/consulting/financial-services/fintech/fintech-insights/chatbot-the-intelligentbanking-assistant. Html

30. Fintech Trends Report: India 2017. https://www.pwc.in/assets/ pdfs/publications/2017/fintech-indiareport-2017.pdf

31. How AI is Disrupting the Banking Sector in India. Silicon India.

32. https://technology.siliconindiamagazine.com/viewpoint/ceo-insights/how-ai-isdisrupting-the-bankingsector-in-india-nwid-9820.html

33. ICICI Bank introduces 'Software Robotics' to power banking operations.

34. https://www.icicibank.com/aboutus/article.page?identifier=news-icici-bank-introducessoftwarerobotics-to-power-banking-operations-20160809103646464 